\title{
Physical Fitness Is Independently Related to Blood Leptin Concentration and Insulin Sensitivity Index in Male Subjects with Central Adiposity
}

\author{
Mohamed Ali Saafi $^{a}$ Delphine Frere-Meunier ${ }^{b}$ Léonard Feasson ${ }^{b}$ \\ Nadia Boutahar ${ }^{a}$ Christian Denis ${ }^{a}$ \\ a Laboratoire de Physiologie de I'Exercice, EA 4338, Université de Lyon, ${ }^{b}$ Centre Hospitalier \\ Universitaire, Saint-Etienne, France
}

\begin{abstract}
Key Words
Central adiposity • Metabolic syndrome $\cdot$ Maximal power output $\cdot$ Physical fitness $\cdot$ Leptin $\cdot$ Insulin sensitivity
\end{abstract}

\begin{abstract}
Aim: To compare the maximal power output (MPO) of subjects presenting a central adiposity to those of controls and to study the links between plasma leptin or indices of insulin sensitivity (QUICKI) and physical fitness (PF). Methods: MPO was determined for 169 middleaged men divided into two groups according to waist circumference $(\mathrm{WC}-<94 \mathrm{~cm}, \mathrm{WC}+\geq$ $94 \mathrm{~cm}$ ) each subdivided in two subgroups with low and high PF (WC-L, WC-H, WC+L, WC+H) determined from the median MPO relative to fat free mass (3.06 W/ $/ \mathrm{kg}_{\mathrm{FFM}}$ ). Results: MPO (W/ $\mathrm{kg}_{\mathrm{FFM}}$ ) was lower in WC+ than in WC-. Expressed relative to fat mass, leptin was lower and QUICKI higher in WC- than in WC+. In WC+H, leptin and QUICKI were significantly less disturbed than in $W C+L$ and were independently correlated to MPO $(r=-0.36$ and $r=0.32$ respectively; $\mathrm{p}<0.001$ ). In $\mathrm{WC}+$, when visceral perimeter was added to the analysis, the relationships MPO/leptin remained significant but not MPO/QUICKI. Conclusion: The low PF in subjects with abdominal obesity is independently linked to plasma leptin and insulin sensitivity even if leptin and insulin may share common pathways in their peripheral effects. Visceral adiposity participates to the link between MPO and QUICKI, but not between MPO and leptin.
\end{abstract}




\section{Introduction}

Obesity is associated with an increase in mortality [1] and in cardiovascular disease [2]. Within obesity, the accumulation of visceral fat at the abdominal level is a specific marker of these increased risks combined to a cluster of metabolic abnormalities often referred to as metabolic syndrome [3]. Currently, a simple, reliable tool for determining levels of abdominal adiposity is the use of waist circumference (WC) measurements, which have been shown to be a predictive tool for the evaluation of cardiovascular $[4,5]$ or metabolic [6] risks. As illustrated in an early epidemiological study [7], increased cardiovascular risk under central obesity is inversely related to occupational activity. Sports and physical leisure activities are also inversely related to WC [8]. For a given BMI, WC was found lower in subjects with high than in those with low cardiorespiratory fitness [9]. Moreover, a decrease in maximal exercise capacity is related to abdominal adiposity in subjects with type 2 diabetes [10]. Consequently, along with the incidence of diet as a main contributor to energy balance and to body weight changes [11], there would be a vicious circle between physical inactivity and abdominal obesity [12], each of these factors being independent mortality predictors while physical inactivity would be a stronger causal element than obesity [13].

Insulin resistance has been widely described in strong relationship with human obesity $[2,3]$ and is thought to have a role in obesity-induced cardiovascular diseases [14]. Insulin resistance in overweight or obese subjects decreases following exercise training $[15,16]$ and can be predicted by the level of physical fitness (PF) [6]. Among the network of factors that potentially alter the insulin sensibility is leptin [17]. The peripheral effects of leptin through its receptors, especially in muscles, have pivotal roles in metabolic and insulin signalling modulation in obesity [18]. High levels of plasma leptin in obese humans associated with the decrease of its peripheral effects lead to the concept of leptin resistance [19]. This resistance is at least partly due to down-regulation of the leptin receptors of skeletal muscle [20]. On the other hand, elevated blood leptin concentrations may trigger for cardiac dysfunctions [21]. The coronary flow velocity reserve as a marker of cardiac microvascular function in healthy adults was shown to be linked either positively to PF (maximal power, $\mathrm{W} / \mathrm{kg}$ ) or negatively to blood leptin concentration [22]. Significant relationships were also observed between physical activity energy expenditure and leptin concentration $[23,24]$.

Using simple morphological, physiological and biological data about abdominal adiposity, $\mathrm{PF}$, insulin sensitivity and plasma leptin concentration, we thought to reinvestigate the following questions: Is maximal exercise capacity linked to leptin concentration and insulin resistance in middle-aged men with visceral adiposity? Are these potential relations independent of fat mass and of visceral fat?

Consequently, the aim of the present study was i) to study a sample of middle-aged healthy men comprising subjects with abdominal adiposity and to compare them to lean control subjects of the same age, ii) to measure the maximal exercise capacity of this human sample, and iii) to examine plasma leptin concentration and indexes of insulin resistance and their potential relationships with maximal exercise capacity.

\section{Material and Methods}

Institutional Approval

This investigation was approved by the Committee governing Medical Research in Human Subjects in the University Hospital of Saint Etienne (CPP, decision $n^{\circ} 200519$ ). Subjects were informed of all procedures and gave their written informed consent before testing. 
Subjects

This cross-sectional report was initiated for the design of a further interventional study on the potential effects of exercise training in overweighed middle-aged men. The sample was constituted in response to a newspaper article directed at 45- to 65-year-old male subjects living in the town of Saint Etienne and its suburbs. The article called for volunteers and explained that we required 20 subjects with abdominal obesity to be included in a physical training program. The physiological characteristics of the responders were wider than expected since a lot of normal-weight subjects were interested in participating. The participants were referred to the Clinical Physiology and Exercise Department. There the subjects were questioned about their personal history of hypertension (HT), diabetes mellitus or impaired glucose tolerance, and dyslipidemia. Others topics such as medical treatment, smoking, and personal physical activity were reported. All subjects underwent a standardized clinical examination, and those presenting any chronic illness, with the exception of HT, dyslipidemia and type 2 diabetes, were excluded. Subsequently, a general medical and biological examination was completed for the 169 subjects of the present study, before their final inclusion in the training program. All interviews and examinations were carried out by the same medical investigator (M.A.S.). This investigation was approved by the Committee governing Medical Research in Human Subjects in the University Hospital of Saint Etienne (decision $\mathrm{n}^{\circ}$ 200519) according to the French law and to the Declaration of Helsinki. Subjects were informed of all procedures and gave their written informed consent before testing.

\section{Anthropometric and Clinical Measurements}

Body weight (BW; kg) and height (m) were measured, and BMI kg/m² was calculated. With the subject standing and breathing normally, WC ( $\mathrm{cm}$ ) determined with a tape measure was taken at the point midway between the costal margin and crest in the mid-auxiliary line, as was hip circumference at the widest point around the greater trochanter [25]. The waist-to-hip ratio (WHR) was calculated. Skin fold thicknesses were measured at four sites (triceps, biceps, suprailiacally (Ssi) and subscapularily) using a Holtain skin fold calliper. Fat (FM) and fat free mass (FFM) distributions were estimated according to [26].

The visceral circumference (VC) was estimated as follows:

$\mathrm{VC}=2 \Pi((\mathrm{WC} / 2 \Pi)-(\mathrm{Ssi} / 2))$ with

VC, WC and Ssi expressed in cm. VC was considered as an indicator of the intra-abdominal volume. As such, this factor was appraised after integrating WC as a circle circumference. As this estimation was not supported by referenced procedures, 30 measurements of anatomical VC (RM imaging) were compared to the estimate of $\mathrm{VC}$ in a subset of WC+ subjects of this study. Means are similar $(95.9 \pm 11.7$ and $96.7 \pm$ $5.5 \mathrm{~cm})$, the correlation between paired measurements is significant $(r=0.69, \mathrm{p}<0.0001)$ while moderate in precision (mean difference \pm SD of the difference $=0.88 \pm 8.9 \mathrm{~cm}$ ).

\section{Biochemical and Hormonal Assays}

Venous blood was collected in the early morning on 12-hour fasting subjects. Total cholesterol (TC), high-density lipoprotein cholesterol (HDL-C), triglyceride (TG), apolipoprotein-A1 (Apo-A1), apolipoprotein-B (Apo-B), C-reactive protein, plasma glucose, glycosyl hemoglobin type A1c (HbA1c) were determined in the Hospital's Biochemistry Laboratory. Low-density lipoprotein (LDL-C) was determined indirectly by using Friedewald's formula: $\mathrm{LDL}=\mathrm{TC}-\mathrm{HDL}+(\mathrm{TG} / 5)$. Leptin and insulin were determined with radioimmunoassay kits (Linco Research, St. Charles, MO, USA) at the Hospital's Nuclear Medicine Laboratory. The quantitative insulin sensitivity check index (QUICKI) was calculated as follows : QUICKI = 1/ $(\log$ fasting serum insulin $(\mu \mathrm{U} / \mathrm{ml})+\log$ fasting plasma glucose $(\mathrm{mg} / \mathrm{dl}))[27,28]$.

\section{Maximal Power Output (MPO)}

Respiratory gas exchange measurements could not be engaged in the whole group. The level of MPO (Watts) was measured during a progressive to maximal cycle ergometer protocol using a Monark cycle ergometer (Ergomeca 839E; Monarko, Varberg, Sweeden). The pedalling rate was targeted at 75 pedal rotations per minute. The exercise test began with a 4-min warm-up at $20 \mathrm{~W}$, and then the work rate was increased by $10 \mathrm{~W}$ every minute. The test stopped when power output and pedalling rate could not be sustained by the subject despite energetic verbal encouragement. MPO was taken as that of the last 1-min stage before exhaustion. The mean total duration of the exercise stress was $20 \mathrm{~min}$ (range 12-33 min). To check that a true maximal exercise was achieved, heart rate (from ECG) at the end of exercise and blood lactate concentration (from a fingertip, YSI 2300; YSI Inc. Life Sciences, Yellow Springs, OH, USA ) at the 
3rd minute of recovery were measured. The metabolic link between MPO and maximal oxygen uptake obtained by respiratory gas exchanges was verified by 40 measurements in a subset of overweight subjects of this study. The linear relation was highly significant $(\mathrm{r}=0.92)$, leading to the following equation: MPO $(\mathrm{W})=74.9 \mathrm{VO}_{2}(\mathrm{l} / \mathrm{min})-14.8$, with $\mathrm{MPO}$ ranging from 120 to $274 \mathrm{~W}$ (mean $=193 \mathrm{~W}$ ) and $\mathrm{VO}_{2}$ ranging from 1.70 to $3.84 \mathrm{l} / \mathrm{min}$ (mean $=2.77 \mathrm{l} / \mathrm{min})$.

\section{Statistical Analysis}

The data are expressed as mean \pm SD. The analyses were conducted with StatviewT software (version 5.0; SAS Institute, Cary, NC, USA). Distribution statistics were calculated to determine whether assumptions of normality were acceptable (ie skewness and kurtosis $<2.0$ ). For TGs, glucose, insulin, leptin and QUICKI, the hy pothesis of compatibility to normality could not be accepted. Therefore, these data were log transformed for statistical analysis; the raw data are presented in the text and tables for more meaningful comparisons. From WC measurements on the 169 subjects, a control group was constituted with the subjects having $\mathrm{WC}<94 \mathrm{~cm}(\mathrm{WC}-; \mathrm{n}=47$ ); the remaining subjects with $\mathrm{WC} \geq 94 \mathrm{~cm}$ constituted the abdominal obesity group $(\mathrm{WC}+; \mathrm{n}=122)$. This was followed, using the median calculated from MPO expressed relative to FFM on all subjects, by subdividing each group as low (WC-L, WC+L) or high (WC-H, $\mathrm{WC}+\mathrm{H}$ ) aerobic capacity. This methodological choice permitted to compare subjects with similar low MPO and high MPO in the normal-weight and overweight groups where MPO was determined with the same methodology.

Categorical variables were compared using ANOVAs associated with post-hoc tests. Correlation coefficients were calculated to assess the degree of association between variables. To control that a given significant linear correlation is not due to another variable, partial correlation coefficients were calculated between MPO, leptin, QUICKI and VC. This partial correlation procedure allows verifying a given correlation between two variables when other correlated factors are considered as constant.

\section{Results}

Table 1 shows the characteristics of the 169 men that took part in this study. The sample was separated in two groups with respect to WC (cutting off $=94 \mathrm{~cm}$ ). The sticking difference between the 2 groups is present for morphological, metabolic (except total cholesterol), and exercise parameters.

The median for MPO calculated from the 169 subjects was $3.06 \mathrm{~W} / \mathrm{kg}_{\mathrm{FFM}}$. After each group (WC-, WC+) was subdivided in 2 subsets with median MPO as separating limit, aerobic fitness is found similar between WC-L and WC+L (1 factor ANOVA; table 2). However, it can be pointed out that in $\mathrm{WC}+$, fitter subjects are significantly characterized by lower adiposity, either by WC or FM estimates, lower leptin, and higher QUICKI than low-fit subjects (table 3).

Due to the expected significant correlation between FM and either leptin ( $\mathrm{r}=0.77 ; \mathrm{p}<$ $0.0001)$ or QUICKI $(r=-0.57 ; p<00001)$ the expression of blood leptin concentration and QUICKI relative to FM permits to illustrate that the difference between $\mathrm{WC}+\mathrm{L}$ and $\mathrm{WC}+\mathrm{H}$ remains significant for leptin (fig. 1) and for QUICKI (fig. 2).

In line with ANOVA analysis, leptin and QUICKI, both expressed relative to FM, are significantly correlated to MPO/FFM whatever the groups were (table 4; fig. 3). In order to verify if the correlation between MPO and either leptin or QUICKI are not only due to the functional link between leptin and QUICKI ( $r=-0.48$ and $-0.38 ; \mathrm{p}<0.001$ for whole group and $\mathrm{WC}+$ respectively), a partial correlation analysis was conducted (table 4). Following partial correlation analysis, MPO remains correlated both to leptin after controlling for QUICKI and to QUICKI after controlling for leptin in the whole group $(\mathrm{r}=-0.28 ; \mathrm{p}<0.001$ and $r=0.35$, respectively ; $p<0.001)$ and in the $\mathrm{WC}+(\mathrm{r}=-0.27 ; \mathrm{p}<0.01$ and $\mathrm{r}=0.21$, respectively; $\mathrm{p}<0.05$ ) group (table 4 ).

Due to the fact that abdominal obesity is partitioned between visceral and subcutaneous fat, VC, introduced as controlling factor, invalidates the existent correlation between 
Table 1. Subject characteristics ${ }^{\mathrm{a}}$

\begin{tabular}{|c|c|c|c|}
\hline & $\begin{array}{l}\text { Control (WC-) } \\
(\mathrm{n}=47)\end{array}$ & $\begin{array}{l}\text { Central obesity } \\
(\mathrm{WC}+) \\
(\mathrm{n}=122)\end{array}$ & $\mathrm{p}$ value \\
\hline \multicolumn{4}{|l|}{ Morphometry } \\
\hline Age, years & $55 \pm 5$ & $57 \pm 6$ & n.s. \\
\hline Height, m & $1.71 \pm 0.06$ & $1.72 \pm 0.07$ & n.s. \\
\hline $\mathrm{BW}, \mathrm{kg}$ & $72 \pm 6$ & $88 \pm 11$ & $<0.0001$ \\
\hline BMI, $\mathrm{kg} / \mathrm{m}^{2}$ & $25 \pm 2$ & $30 \pm 4$ & $<0.0001$ \\
\hline $\mathrm{WC}, \mathrm{cm}$ & $87 \pm 4$ & $104 \pm 8$ & $<0.0001$ \\
\hline WHR & $0.93 \pm 0.03$ & $1.01 \pm 0.04$ & $<0.0001$ \\
\hline $\mathrm{VC}, \mathrm{cm}$ & $81 \pm 3$ & $94 \pm 7$ & $<0.0001$ \\
\hline $\mathrm{SSi}, \mathrm{mm}$ & $20 \pm 7$ & $32 \pm 8$ & $<0.0001$ \\
\hline$\% \mathrm{FM}$ & $26 \pm 4$ & $34 \pm 5$ & $<0.0001$ \\
\hline $\mathrm{FM}, \mathrm{kg}$ & $19 \pm 4$ & $30 \pm 7$ & $<0.0001$ \\
\hline$\%$ FFM & $74 \pm 4$ & $66 \pm 5$ & $<0.0001$ \\
\hline FFM, kg & $53 \pm 4$ & $58 \pm 6$ & $<0.0001$ \\
\hline \multicolumn{4}{|l|}{ Metabolism } \\
\hline Total cholesterol, mmol/l & $5.3 \pm 0.9$ & $5.4 \pm 1.0$ & 0.50 \\
\hline HDL-cholesterol, mmol/l & $1.5 \pm 0.3$ & $1.3 \pm 0.3$ & $<0.01$ \\
\hline Triglycerides, mmol/l & $1.1 \pm 0.6$ & $1.5 \pm 1.0$ & $<0.0001$ \\
\hline Fasting glucose, $\mathrm{mmol} / \mathrm{l}$ & $5.2 \pm 1.0$ & $5.8 \pm 1.3$ & $<0.01$ \\
\hline Insulin, mU/l & $5.2 \pm 3.4$ & $9.9 \pm 6.5$ & $<0.0001$ \\
\hline QUICKI & $0.39 \pm 0.04$ & $0.34 \pm 0.04$ & $<0.0001$ \\
\hline Leptin, $\mu \mathrm{g} / \mathrm{l}$ & $4.0 \pm 1.8$ & $10.0 \pm 5.9$ & $<0.0001$ \\
\hline \multicolumn{4}{|l|}{ Exercise } \\
\hline Maximal power output, W & $191 \pm 42$ & $170 \pm 37$ & $<0.01$ \\
\hline Maximal heart rate, bpm & $173 \pm 12$ & $163 \pm 15$ & $<0.0001$ \\
\hline Peak blood lactate, $\mathrm{mmol} / \mathrm{l}$ & $11.6 \pm 2.4$ & $10.5 \pm 2.4$ & $<0.01$ \\
\hline
\end{tabular}

QUICKI/FM and MPO in WC+ (table 5). However, VC is strongly negatively correlated with QUICKI/FM ( $r=-0.67 ; p<0.001)$, but not with leptin/FM (table 5), which illustrates the wellknown worsening effect of visceral adiposity upon insulin resistance.

To summarize, the link between MPO and leptin observed in $\mathrm{WC}+$ is independent of QUICKI and VC. However, the correlation between MPO and QUICKI appears to be dependent on VC.

\section{Discussion}

The present study illustrates that abdominal obesity (WC+) is accompanied by a lower MPO than in control subjects (WC-). The main result is that such a low MPO is statistically independently linked to both blood leptin concentration and to QUICKI, even if these parameters are expressed relative to FM. 
Table 2. Values of MPO expressed absolute (Watts) or relative to BW or FFM

\begin{tabular}{clll}
\hline & \multicolumn{2}{l}{ MPO } & \\
\cline { 2 - 4 } & Watts & Watts $/ \mathrm{kg}_{\text {BW }}$ & Watts $/ \mathrm{kg}_{\text {FFM }}$ \\
\hline Mean values \pm SD & & & \\
WC-L $(\mathrm{n}=11)$ & $142 \pm 19$ & $1.97 \pm 0.25$ & $2.64 \pm 0.28$ \\
WC-H $(\mathrm{n}=36)$ & $206 \pm 35$ & $2.89 \pm 0.58$ & $3.91 \pm 0.71$ \\
WC+L $(\mathrm{n}=72)$ & $147 \pm 24$ & $1.65 \pm 0.28$ & $2.51 \pm 0.36$ \\
WC+H (n=50) & $202 \pm 26$ & $2.36 \pm 0.29$ & $3.53 \pm 0.33$ \\
\hline ANOVA & $\mathrm{p}<0.0001$ & $\mathrm{p}<0.0001$ & $\mathrm{p}<0.0001$ \\
\hline Post-hoc tests after ANOVA & & & \\
WC-L versus WC-H & $\mathrm{p}<0.0001$ & $\mathrm{p}<0.0001$ & $\mathrm{p}<0.0001$ \\
WC-L versus WC+L & $\mathrm{p}=0.54$ & $\mathrm{p}<0.01$ & $\mathrm{p}=0.40$ \\
WC-L versus WC+H & $\mathrm{p}<0.0001$ & $\mathrm{p}<0.01$ & $\mathrm{p}<0.0001$ \\
WC-H versus WC+L & $\mathrm{p}<0.0001$ & $\mathrm{p}<0.0001$ & $\mathrm{p}<0.0001$ \\
WC-H versus WC+H & $\mathrm{p}=0.49$ & $\mathrm{p}<0.0001$ & $\mathrm{p}<0.001$ \\
WC+L versus WC+H & $\mathrm{p}<0.0001$ & $\mathrm{p}<0.0001$ & $\mathrm{p}<0.0001$ \\
\hline
\end{tabular}

Table 3. Analysis of variance through the 4 subgroups

\begin{tabular}{|c|c|c|c|c|}
\hline & WC, $\mathrm{cm}$ & FM, kg & Leptin, $\mu \mathrm{g} / 1$ & QUICKI \\
\hline \multicolumn{5}{|l|}{ Mean values \pm SD } \\
\hline WC-L $(n=11)$ & $87.2 \pm 3.9$ & $18.2 \pm 4.0$ & $3.8 \pm 1.4$ & $0.38 \pm 0.03$ \\
\hline WC-H $(n=36)$ & $87.5 \pm 4.5$ & $18.8 \pm 4.0$ & $4.1 \pm 1.9$ & $0.39 \pm 0.05$ \\
\hline$W C+L(n=72)$ & $105.7 \pm 9.2$ & $31.4 \pm 7.6$ & $11.5 \pm 6.7$ & $0.34 \pm 0.04$ \\
\hline $\mathrm{WC}+\mathrm{H}(\mathrm{n}=50)$ & $100.6 \pm 5.8$ & $28.8 \pm 6.1$ & $7.9 \pm 3.8$ & $0.35 \pm 0.03$ \\
\hline ANOVA & $\mathrm{p}<0.0001$ & $\mathrm{p}<0.0001$ & $\mathrm{p}<0.0001$ & $\mathrm{p}<0.0001$ \\
\hline \multicolumn{5}{|c|}{ Post-hoc tests after ANOVA } \\
\hline WC-L versus WC-H & $p=0.89$ & $p=0.78$ & $p=0.99$ & $\mathrm{p}=0.27$ \\
\hline WC-L versus $W C+L$ & $\mathrm{p}<0.0001$ & $\mathrm{p}<0.0001$ & $\mathrm{p}<0.0001$ & $\mathrm{p}<0.001$ \\
\hline WC-L versus $\mathrm{WC}+\mathrm{H}$ & $\mathrm{p}<0.0001$ & $\mathrm{p}<0.0001$ & $\mathrm{p}<0.001$ & $\mathrm{p}=0.06$ \\
\hline WC-H versus WC+L & $\mathrm{p}<0.0001$ & $\mathrm{p}<0.0001$ & $\mathrm{p}<0.0001$ & $\mathrm{p}<0.0001$ \\
\hline WC-H versus $\mathrm{WC}+\mathrm{H}$ & $\mathrm{p}<0.0001$ & $\mathrm{p}<0.0001$ & $\mathrm{p}<0.001$ & $\mathrm{p}<0.0001$ \\
\hline $\mathrm{WC}+\mathrm{L}$ versus $\mathrm{WC}+\mathrm{H}$ & $\mathrm{p}<0.001$ & $\mathrm{p}<0.03$ & $\mathrm{p}<0.001$ & $\mathrm{p}<0.01$ \\
\hline
\end{tabular}

The reliability of MPO as an indicator for peak aerobic power and, by additionally measuring peak oxygen consumption $\left(\mathrm{O}_{2 \text { peak }}\right)$, for aerobic $\mathrm{PF}$ is generally accepted when an incremental exercise is performed on a mechanically break-loaded cycle ergometer until voluntary exhaustion [29]. This general concept could be applied in our laboratory when considering the highly significant correlation obtained between MPO and $\mathrm{V}_{02 \text { peak }}$ in a subset of WC+ subjects (see 'Material and Methods'). The higher MPO observed in WC- than in WC+ is significant whether expressed in gross value, relative to body weight or to FFM. Previous 


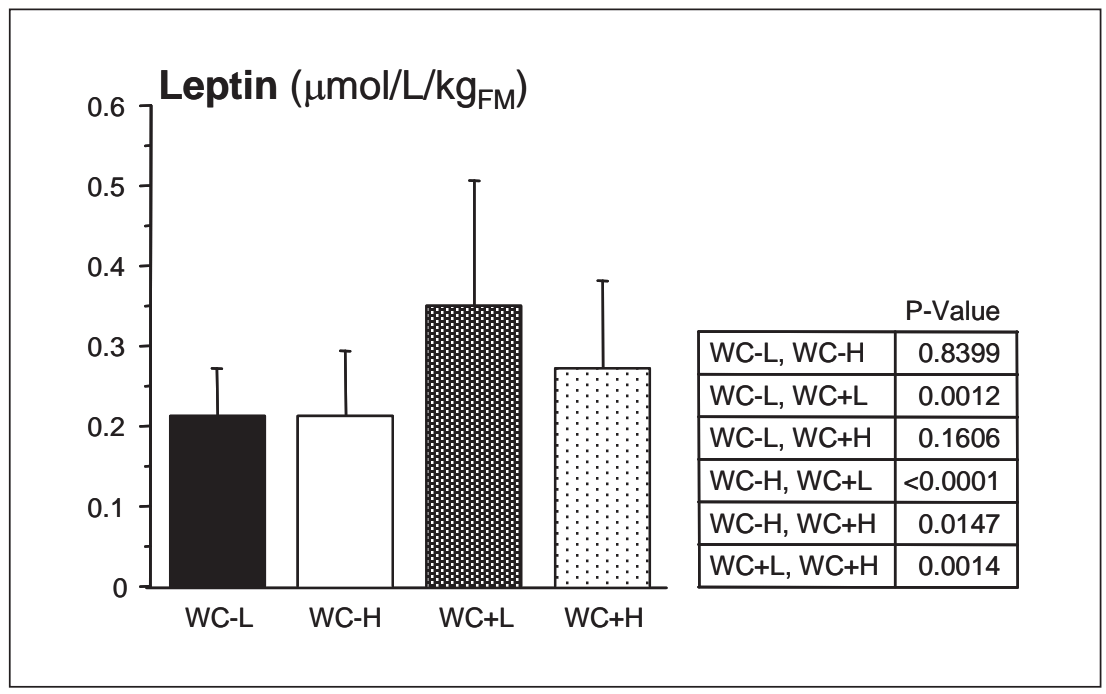

Fig. 1. Blood leptin concentration relative to fat mass in the different subgroups (for abbreviations see text). Bars denote standard deviation. Statistical comparisons of means were obtained from ANOVA and post-hoc tests.

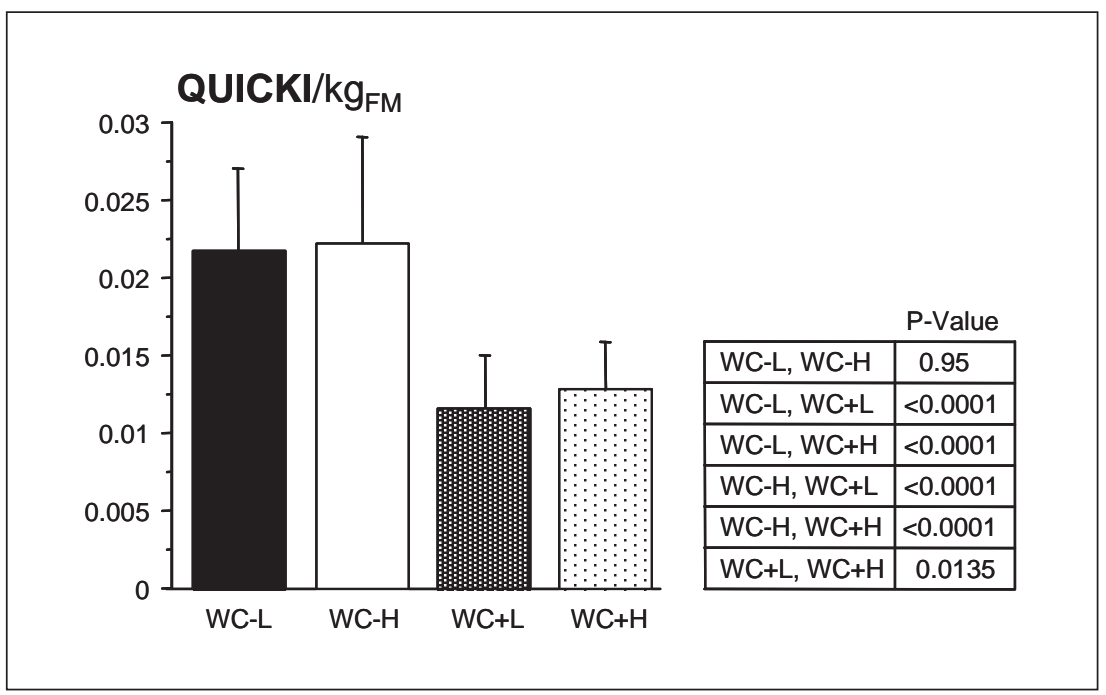

Fig. 2. QUICKI relative to fat mass in the different subgroups (for abbreviations see text). Bars denote standard deviation. Statistical comparisons of means were obtained from ANOVA and post-hoc tests.

studies did not distinguish such a difference of PF between normal-weight and overweight adult subjects when expressed in terms of MPO or $\mathrm{V}_{02 \text { peak }}[30,31]$. Two biases could have been introduced in our results. First of all, it could be questioned if $\mathrm{WC}+$ subjects really achieved maximal exercise. By reference to heart rate at exhaustion, it would be doubtful. However, the mean blood lactate concentration $(>10 \mathrm{mmol} / \mathrm{l})$ is a strong parameter of maximal metabolic stress. As the exercise tests were conducted by the same professionals in a random order for the 169 subjects, at least the 'near to maximal' exercise stress could 


\section{$A$ Leptin $\left(\mu \mathrm{mol} / \mathrm{L} / \mathrm{kg}_{\mathrm{FM}}\right)$}
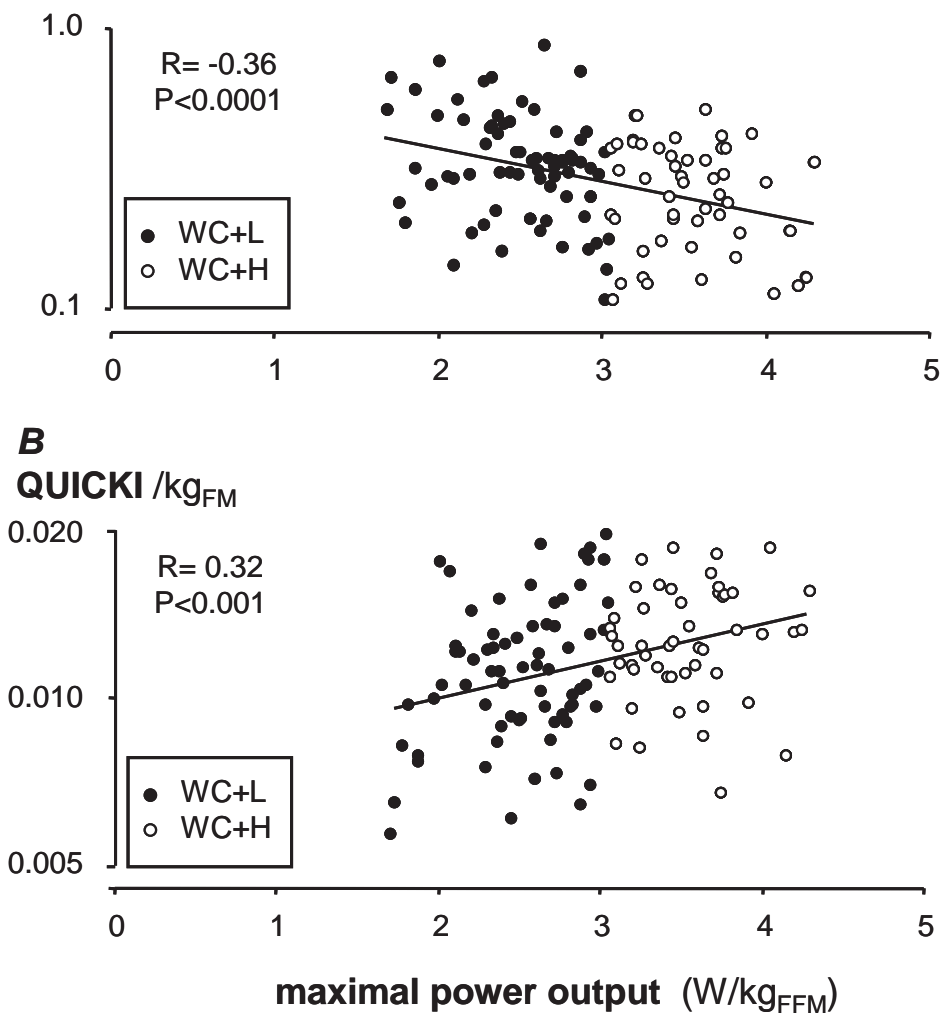

Fig. 3. Correlations of $\mathbf{A}$ blood leptin concentration and $\mathbf{B}$ QUICKI both expressed relative to fat mass, with maximal power output (W/ $\left.\mathrm{kg}_{\mathrm{FFM}}\right)$.

be retained. Secondly, in our procedure of recruitment the calling paper was directed toward $\mathrm{WC}+$ subjects in the aim to constitute an exercise training study. In fact, most of the responders were overweight but a lower part was constituted of WC- subjects who were also interested in participating to an exercise training program. They were previously more active than their overweight counterparts. It is likely that lean sedentary subjects do not respond while overweight sedentary subjects do due to medical preventive reasons.

In order to investigate the aerobic power of muscle tissue, we choose to focus the statistical analysis on MPO relative to FFM [32]. At least in middle-aged men, studies with expression of PF relative to FFM are scarce. In a recent study on 14 young adult monozygotic twin pairs, where one twin presented an acquired obesity with regard to his normal-weight co-twin, $\mathrm{V}_{02 \text { peak }}$ and MPO were found to be lower in the overweight twin when expressed relative to FFM [33]. Consequently these results suggest that the FFM unit, in which muscle represents almost half, would be less aerobically powerful in $\mathrm{WC}+$ than in control subjects. A lower mitochondrial function could be related to the decreased PF in WC+ both at the skeletal muscle [34] and myocardial [35] levels. With respect to maximal exercise, central cardiocirculatory dysfunction may be more suspected than skeletal muscle dysfunction. Interestingly, weight loss either by exercise training [36] or by diet [37] can improve cardiac function in obese adults. The clinical consequences of obesity and PF and their respective 
Table 4. Simple and partial correlations between MPO and leptin or QUICKI in the whole sample or in $\mathrm{WC}-$ and $\mathrm{WC}+$ subgroups $^{\mathrm{a}}$

\begin{tabular}{|c|c|c|c|c|c|c|}
\hline & \multicolumn{6}{|c|}{ MPO/FFM } \\
\hline & \multicolumn{2}{|c|}{ whole $(n=169)$} & \multicolumn{2}{|c|}{$W C-(n=47)$} & \multicolumn{2}{|c|}{$W C+(n=122)$} \\
\hline & $\mathrm{r}$ & partial r & $\mathrm{r}$ & partial $r$ & $\mathrm{r}$ & partial $\mathrm{r}$ \\
\hline Leptin whole & $-0.45^{* * *}$ & $-0.28^{* * *}$ & & & & \\
\hline QUICKI whole & $0.49^{* * *}$ & $0.35^{* * *}$ & & & & \\
\hline Leptin WC- & & & $-0.38^{* *}$ & $-0.33^{*}$ & & \\
\hline QUICKI WC- & & & $0.30^{*}$ & 0.24 & & \\
\hline Leptin WC+ & & & & & $-0.36^{* * *}$ & $-0.27 * *$ \\
\hline QUICKI WC+ & & & & & $0.32^{* * *}$ & $0.21^{*}$ \\
\hline
\end{tabular}

aLeptin and QUICKI are expressed relative to FM.

${ }^{*} \mathrm{p}<0.05 ;{ }^{* *} \mathrm{p}<0.01 ;{ }^{* * *} \mathrm{p}<0.001$.

Table 5. Simple and partial correlations between MPO and leptin, QUICKI or VC in WC+ subgroup

\begin{tabular}{|c|c|c|c|c|c|c|}
\hline \multirow{2}{*}{$\begin{array}{l}\text { WC+ } \\
(n=122)\end{array}$} & \multicolumn{2}{|c|}{ MPO/FFM } & \multicolumn{2}{|c|}{ Leptin/FM } & \multicolumn{2}{|c|}{ QUICKI/FM } \\
\hline & $r$ & partial r & $r$ & partial r & $r$ & partial r \\
\hline MPO/FFM & 1.0 & 1.0 & & & & \\
\hline leptin/FM & $-0.36^{* * *}$ & $-0.26^{* *}$ & 1.0 & 1.0 & & \\
\hline QUICKI/FM & $0.32^{* * *}$ & -0.07 & $-0.38^{* * *}$ & $-0.23^{*}$ & 1.0 & 1.0 \\
\hline VC & $-0.45^{* * *}$ & $-0.33^{* * *}$ & $0.32^{* * *}$ & -0.02 & $-0.72^{* * *}$ & $-0.67^{* * *}$ \\
\hline
\end{tabular}

interactions are complex. While WC could have been described as a better predictor of cardiovascular disease than aerobic fitness [38], it remains that improvement in PF decreases the incidence of metabolic syndrome [39] and the risk of cardiovascular diseases [40].

Within the WC+ group, plasma leptin, insulin resistance index and FM were significantly more elevated in the low $(\mathrm{WC}+\mathrm{L})$ than in the high $(\mathrm{WC}+\mathrm{H}) \mathrm{PF}$ group. Differences for leptin and QUICKI remain significant when expressed relative to FM. This finding raises the question of whether the level of PF may interact with the regulatory metabolic mechanisms in which leptin and insulin are involved.

The relationship between leptin concentrations and aerobic $P F$ was previously presented by Kiviniemi et al. [22] but was not observed by others [23, 41]. Sabatier et al. [40] studied women and found however that the cardiovascular consequence of leptin and fatness through increased arterial pressure can be diminished by the level of PF. In the study of Franks et al. [23], PF was estimated as $\mathrm{V}_{\text {02peak }}$ from a submaximal exercise extrapolated to theoretical maximum heart rate (220 - age). In this same study, the physical activity energy expenditure (PAEE) was also estimated, showing a significant negative correlation with blood leptin. These results were comforted by another study by the same team with the 
description of the consistent link between baseline leptin and both the decline in physical activity and worsening in insulin resistance during a 5-year follow-up [24]. It is out of the scope of the present study to discuss the respective interests to use estimates of daily energy expenditure or of maximal aerobic fitness in determinants of metabolic homeostasis. We also tried to point out PAEE in the present study by a validated (against $\mathrm{V}_{\text {O2peak }}$ ) questionnaire procedure [42]. Questionnaires were administered for autofilling by each subject which probably leads to uncertain data capture (data not shown); this is in line with debates upon the use of self-reported questionnaires to assess physical activity [42]. Independently, the level of physical activity was also grossly interpreted during the interview preceding the medical examination. While there are significantly more active subjects in $\mathrm{WC}+\mathrm{H}$ than in $\mathrm{WC}+\mathrm{L}$ (and so on in the WC- subgroup, data not shown), the two classifications (PF by MPO measurement and physical activity by interview) are far from being superimposed. Nevertheless, the approach of Franks et al. [23] of measuring physical activity based on 4-day recording of heart rate in relation with an individual work rate versus heart rate relationship (Flex Heart Rate technique) likely brings higher precision in PAEE determination [23, 24]. To summarize, the present results add further evidence in line with the relation that may exist between blood leptin concentration and either PF or PAEE in adults with visceral adiposity.

Several studies have emphasized the involvement of leptin in muscle metabolism. In normal-weight subjects, leptin stimulates fatty acid oxidation and glucose uptake in muscle tissue [17]. These effects are mainly direct and controlled by the muscle's AMP-activated kinase (AMPK) but also indirect secondarily through central pathways [43]. In obese subjects with excess muscle fatty acids, where there is leptin resistance which is characterized by an increase in circulating leptin, AMPK-induced fatty acid oxidation is impaired [18], leading to accumulation of triacylglycerol and long-chain fatty acids in the muscles which is responsible for ceramide synthesis and the appearance of insulin resistance [44]. In addition, through AMPK activation and the following deacetylation of peroxisome proliferator-activated receptor- $\gamma$ coactivator $1 \alpha(\mathrm{PGC}-1 \alpha)$, leptin participates to mitochondrial biogenesis in muscle [45]. The concept of selective leptin resistance in muscle, which is associated with central adiposity, can lead to a decrease in the oxidative capacity of skeletal and myocardial muscle [35]. During exercise, this basal metabolic environment may disturb the capacity of skeletal muscle to reach maximal power and myocardium to permit maximal cardiac output. These data suggest that muscle leptin resistance may be one of the factors which are implicated in the decline of PF observed in subjects with central obesity.

The relation between insulin sensitivity and aerobic PF which is illustrated in the present study was previously shown in healthy men $[6,46]$ and in overweight and obese healthy subjects [47]. These studies outlined the earlier observation of the increased risk for developing impaired fasting glucose and type 2 diabetes in subjects with low physical fitness [48]. It was also demonstrated that $V_{02 p e a k}$ and concomitantly oxidative muscle capacity were strong independent predictors of whole body insulin sensitivity [49]. As stated above, AMPK being activated by exercise and training [50] is a potential contributor to insulin sensitivity through PGC-1 $\alpha$ regulation [51].

In the present study, plasma leptin and QUICKI in the WC+ subgroup appear statistically independently related to PF. This would suggest that cellular mechanisms supporting these links are partly different. One postulated related factor may be visceral obesity (VC) which statistically explains the relation between QUICKI and PF, but does not contribute to the link between leptin and PF. On the other hand, independently of PF, in WC+ subjects who are characterized by high levels of leptin, for a given total body fat an increase in the visceral fat accumulation would be a factor contributing to insulin resistance, as explained by the significant negative simple or partial correlations between QUICKI/FM and VC. This is in line with 
Klöting et al. [52] who demonstrated, in the case of morbid obesity, that subjects may be insulin-sensitive with reference to other insulin-resistant subjects with similar BMI, FM and leptin ,only due to the fact that the former ones have lower visceral fat.

In conclusion, in a group of middle-aged men, subjects identified by WC $\geq 94 \mathrm{~cm}$ demonstrate a lower MPO than those without abdominal obesity. MPO of these subjects with abdominal obesity is related both to blood leptin concentration and QUICKI, independently of total body fat. Visceral area statistically contributes to explain the link between MPO and QUICKI, but not between MPO and leptin. Further studies will be necessary to establish the effects of exercise training on these interrelationships.

\section{Acknowledgments}

This research was supported by a grant from the University Hospital Center through the Regional Direction of Clinical Research (PHRC 2005)

\section{Disclosure Statement}

The authors declared no conflicts of interest.

\section{References}

1 Adams KF, Schatzkin A, Harris TB, Kipnis V, Mouw T, Ballard-Barbash R, Hollenbeck A, Leitzmann MF: Overweight, obesity, and mortality in a large prospective cohort of persons 50 to 71 years old. N Engl J Med 2006; 355:763-778.

2 Van Gaal LF, Mertens IL, De Block CE: Mechanisms linking obesity with cardiovascular disease. Nature 2006;444:875-880.

3 Desprès J, Lemieux I: Abdominal obesity and metabolic syndrome. Nature 2006;444:881-887.

- 4 Rexrode KM, Buring JE, Manson JE: Abdominal and total adiposity and risk of coronary heart disease in men. Int J Obes Relat Metab Disord 2001;25:1047-1056.

5 Freiberg MS, Pencina MJ, D’Agostino RB, Lanier K, Wilson PWF, Vasan RS: Bmi vs. Waist circumference for identifying vascular risk. Obesity (Silver Spring) 2008;16:463-469.

- 6 Racette SB, Evans EM, Weiss EP, Hagberg JM, Holloszy JO: Abdominal adiposity is a stronger predictor of insulin resistance than fitness among 50-95 year olds. Diabetes Care 2006;29:673-678.

- 7 Heady JA, Morris JN, Kagan A, Raffle PA: Coronary heart disease in London busmen. A progress report with particular reference to physique. Br J Prev Soc Med 1961;15:143-153.

- 8 Seidell JC, Cigolini M, Deslypere JP, Charzewska J, Ellsinger BM, Cruz A: Body fat distribution in relation to physical activity and smoking habits in 38-year-old European men. The European fat distribution study. Am J Epidemiol 1991;133:257-265.

- 9 Wong SL, Katzmarzyk P, Nichaman MZ, Church TS, Blair SN, Ross R: Cardiorespiratory fitness is associated with lower abdominal fat independent of body mass index. Med Sci Sports Exerc 2004;36:286-291.

10 Ribisl PM, Lang W, Jaramillo SA, Jakicic JM, Stewart KJ, Bahnson J, Bright R, Curtis JF, Crow RS, Soberman JE: Exercise capacity and cardiovascular/metabolic characteristics of overweight and obese individuals with type 2 diabetes. The look AHEAD clinical trial. Diabetes Care 2007;30:2679-2984.

11 Chaston TB, Dixon JB: Factors associated with percent change in visceral versus subcutaneous abdominal fat during weight loss: findings from a systematic review. Int J Obes (Lond) 2008;32:619-628

12 Pietiläinen KH, Kaprio J, Borg P, Plasqui G, Yki-Järvinen H, Kujala UM, Rose RJ, Westerterp KR, Rissanen A: Physical inactivity and obesity: a vicious circle. Obesity (Silver Spring) 2008;16:409-414.

13 Telford RD: Low physical activity and obesity: causes of chronic disease or simply predictors? Med Sci Sports Exerc 2007;39:1233-1240.

14 Reaven GM: Insulin resistance: the link between obesity and cardiovascular disease. Endocrinol Metab Clin North Am 2008;37:581-601, vii-viii.

15 Gan S K, Kriketos AD, Ellis BA, Thompson CH, Kraegen EW, Chisholm DJ: Changes in aerobic capacity and visceral fat but not myocyte lipid levels predict increased insulin action after exercise in overweight and obese men. Diabetes Care 2003;26:1706-1713. 
16 O'Leary VB, Marchetti CM, Krishnan RK, Stetzer BP, Gonzalez F, Kirwan JP: Exercise-induced reversal of insulin resistance in obese elderly is associated with reduced visceral fat. J Appl Physiol 2006;100:15841589.

17 Stefanyk LE, Dyck DJ: The interaction between adipokines, diet and exercise on muscle insulin sensitivity. Curr Opin Clin Nutr Metab Care 2010;13:255-259.

$\checkmark 18$ Steinberg GR, Parolin ML, Heigenhauser GJ, Dyck DJ: Leptin increases fat oxidation in lean but not obese human skeletal muscle: evidence of peripheral leptin resistance. Am J Physiol Endocrinol Metab 2002; 283:E187-192.

19 Martin SS, Qasim A, Reilly MP: Leptin resistance: a possible interface of inflammation and metabolism in obesity-related cardiovascular disease. J Am Coll Cardiol 2008;52:1201-1210.

-20 Fuentes T, Ara I, Guadalupe-Grau A, Larsen S, Stallknecht B, Olmedillas H, Santana A, Helge JW, Calbet JA, Guerra B: Leptin receptor $170 \mathrm{kDa}$ (OB-R170) protein expression is reduced in obese human skeletal muscle: a potential mechanism of leptin resistance. Exp Physiol 2010;95:160-171.

-21 Ren J: Leptin and hyperleptinemia - from friend to foe for cardiovascular function. J Endocrinol 2004;181: $1-10$.

-22 Kiviniemi AM, Hautala AJ, Makikallio TH, Seppanen T, Huikuri HV, Tulppo MP: Cardiac vagal outflow after aerobic training by analysis of high-frequency oscillation of the R-R interval. Eur J Appl Physiol 2006;96: 686-692.

-23 Franks PW, Farooqi IS, Luan J, Wong MY, Halsall I, O’Rahilly S, Wareham NJ: Does physical activity energy expenditure explain the between-individual variation in plasma leptin concentrations after adjusting for differences in body composition? J Clin Endocrinol Metab 2003;88:3258-3263.

-24 Franks PW, Loos RJ, Brage S, O’Rahilly S, Wareham NJ, Ekelund U: Physical activity energy expenditure may mediate the relationship between plasma leptin levels and worsening insulin resistance independently of adiposity. J Appl Physiol 2007;102:1921-1926.

25 Chan DC, Watts GF, Barrett PH, Burke V: Waist circumference, waist-to-hip ratio and body mass index as predictors of adipose tissue compartments in men. QJM 2003;96:441-447.

-26 Durnin JV, Womersley J: Body fat assessed from total body density and its estimation from skinfold thickness: Measurements on 481 men and women aged from 16 to 72 years. Br J Nutr 1974;32:77-97.

-27 Rabasa-Lhoret R, Bastard J, Jan V, Ducluzeau P, Andreelli F, Guebre F, Bruzeau J, Louche-Pellissier C, MaItrepierre C, Peyrat J, Chagné J, Vidal H, Laville M: Modified quantitative insulin sensitivity check index is better correlated to hyperinsulinemic glucose clamp than other fasting-based index of insulin sensitivity in different insulin-resistant states. J Clin Endocrinol Metab 2003;88:4917-4923.

-28 Katsuki A, Urakawa H, Gabazza EC, Murashima S, Nakatani K, Togashi K, Yano Y, Adachi Y, Sumida Y: Quantitative insulin sensitivity check index is a useful indicator of insulin resistance in japanese metabolically obese, normal-weight subjects with normal glucose tolerance. Endocr J 2005;52:253-257.

29 Jones NL: Clinical Exercise Testing, 4th ed. Philadelphia, W.B. Saunders , 1997.

30 Miller WC, Wallace JP, Eggert KE: Predicting max hr and the HR-VO2 relationship for exercise prescription in obesity. Med Sci Sports Exerc 1993;25:1077-1081.

-31 Salvadori A, Fanari P, Mazza P, Agosti R, Longhini E: Work capacity and cardiopulmonary adaptation of the obese subject during exercise testing. Chest 1992;101:674-679.

32 Goran M, Fields DA, Hunter GR, Herd SL, Weinsier RL: Total body fat does not influence maximal aerobic capacity. Int J Obes Relat Metab Disord 2000;24:841-848.

-33 Mustelin L, Pietilainen KH, Rissanen A, Sovijarvi AR, Piirila P, Naukkarinen J, Peltonen L, Kaprio J, YkiJarvinen H: Acquired obesity and poor physical fitness impair expression of genes of mitochondrial oxidative phosphorylation in monozygotic twins discordant for obesity. Am J Physiol Endocrinol Metab 2008;295:E148-154.

-34 Ritov VB, Menshikova EV, He J, Ferrell RE, Goodpaster BH, Kelley DE: Deficiency of subsarcolemmal mitochondria in obesity and type 2 diabetes. Diabetes 2005;54:8-14.

35 Nisoli E, Clementi E, Carruba MO, Moncada S: Defective mitochondrial biogenesis: A hallmark of the high cardiovascular risk in the metabolic syndrome? Circ Res 2007;100:795-806.

36 Schrauwen-Hinderling VB, Hesselink MK, Meex R, van der Made S, Schar M, Lamb H, Wildberger JE, Glatz J, Snoep G, Kooi ME, Schrauwen P: Improved ejection fraction after exercise training in obesity is accompanied by reduced cardiac lipid content. J Clin Endocrinol Metab 2010;95:1932-1938.

37 Viljanen AP, Karmi A, Borra R, Parkka JP, Lepomaki V, Parkkola R, Lautamaki R, Jarvisalo M, Taittonen M, Ronnemaa T, Iozzo P, Knuuti J, Nuutila P, Raitakari OT: Effect of caloric restriction on myocardial fatty acid uptake, left ventricular mass, and cardiac work in obese adults. Am J Cardiol 2009;103:1721-1726.

-38 Christou DD, Gentile CL, DeSouza CA, Seals DR, Gates PE: Fatness is a better predictor of cardiovascular disease risk factor profile than aerobic fitness in healthy men. Circulation 2005; 111:1904-1914.

-39 LaMonte MJ, Barlow CE, Jurca R, Kampert JB, Church TS, Blair SN: Cardiorespiratory fitness is inversely associated with the incidence of metabolic syndrome: A prospective study of men and women. Circulation 2005;112:505-512.

40 Hainer V, Toplak H, Stich V: Fat or fit: What is more important? Diabetes Care 2009;32(suppl 2):S392-397.

-41 Sabatier MJ, McCully KK, Marinik EL, Schwark EH, Haddow S, Cortez-Cooper M, Bergeron MF, Sloan GJ, Cannon JG: Leptin, blood pressure, and aerobic capacity in women. Am J Hypertens 2008;21:12451250 . 
42 Garet M, Degache F, Costes F, Da-Costa A, Lacour J, Barthelemy J, Roche F: Daqihf: Methodology and validation of a daily activity questionnaire in heart failure. Med Sci Sports Exerc 2004;36:1275-1282.

43 Steinberg GR, Kemp BE: AMPK in health and disease. Physiol Rev 2009;89:1025-1078.

44 Dyck DJ: Leptin sensitivity in skeletal muscle is modulated by diet and exercise. Exerc Sport Sci Rev 2005; 33:189-194.

-45 Li L, Pan R, Li R, Niemann B, Aurich AC, Chen Y, Rohrbach S: Mitochondrial biogenesis and peroxisome proliferator-activated receptor-gamma coactivator-1alpha (PGC-1alpha) deacetylation by physical activity: intact adipocytokine signaling is required. Diabetes 2011;60:157-167.

46 Arsenault BJ, Lachance D, Lemieux I, Almeras N, Tremblay A, Bouchard C, Perusse L, Despres JP: Visceral adipose tissue accumulation, cardiorespiratory fitness, and features of the metabolic syndrome. Arch Intern Med 2007;167:1518-1525.

47 Haufe S, Engeli S, Budziarek P, Utz W, Schulz-Menger J, Hermsdorf M, Wiesner S, Otto C, Haas V, de Greiff A, Luft FC, Boschmann M, Jordan J: Cardiorespiratory fitness and insulin sensitivity in overweight or obese subjects may be linked through intrahepatic lipid content. Diabetes 2010;59:1640-1647.

48 Wei M, Gibbons LW, Mitchell TL, Kampert JB, Lee CD, Blair SN: The association between cardiorespiratory fitness and impaired fasting glucose and type 2 diabetes mellitus in men. Ann Intern Med 1999;130:89-96.

-49 Bruce CR, Anderson MJ, Carey AL, Newman DG, Bonen A, Kriketos AD, Cooney GJ, Hawley JA: Muscle oxidative capacity is a better predictor of insulin sensitivity than lipid status. J Clin Endocrinol Metab 2003; 88:5444-5451.

50 Jorgensen SB, Richter EA, Wojtaszewski JF: Role of AMPK in skeletal muscle metabolic regulation and adaptation in relation to exercise. J Physiol 2006;574:17-31.

51 Lira VA, Benton CR, Yan Z, Bonen A: PGC-1alpha regulation by exercise training and its influences on muscle function and insulin sensitivity. Am J Physiol Endocrinol Metab 2010;299:E145-161.

52 Klöting N, Fasshauer M, Dietrich A, Kovacs P, Schon MR, Kern M, Stumvoll M, Blüher M: Insulin-sensitive obesity. Am J Physiol Endocrinol Metab 2010;299:E506-515. 